\title{
Increased sex ratio in Russia and Cuba after Chernobyl: a radiological hypothesis
}

\author{
Hagen Scherb*, Ralf Kusmierz and Kristina Voigt
}

\begin{abstract}
Background: The ratio of male to female offspring at birth may be a simple and non-invasive way to monitor the reproductive health of a population. Except in societies where selective abortion skews the sex ratio, approximately 105 boys are born for every 100 girls. Generally, the human sex ratio at birth is remarkably constant in large populations. After the Chernobyl nuclear power plant accident in April 1986, a long lasting significant elevation in the sex ratio has been found in Russia, i.e. more boys or fewer girls compared to expectation were born. Recently, also for Cuba an escalated sex ratio from 1987 onward has been documented and discussed in the scientific literature.
\end{abstract}

Presentation of the hypothesis: By the end of the eighties of the last century in Cuba as much as about $60 \%$ of the food imports were provided by the former Soviet Union. Due to its difficult economic situation, Cuba had neither the necessary insight nor the political strength to circumvent the detrimental genetic effects of imported radioactively contaminated foodstuffs after Chernobyl. We propose that the long term stable sex ratio increase in Cuba is essentially due to ionizing radiation.

Testing of the hypothesis: A synoptic trend analysis of Russian and Cuban annual sex ratios discloses upward jumps in 1987. The estimated jump height from 1986 to 1987 in Russia measures 0.51\% with a 95\% confidence interval $(0.28,0.75)$, p value $<0.0001$. In Cuba the estimated jump height measures $2.99 \%(2.39,3.60)$, $p$ value $<0.0001$. The hypothesis may be tested by reconstruction of imports from the world markets to Cuba and by radiological analyses of remains in Cuba for Cs-137 and Sr-90.

Implications of the hypothesis: If the evidence for the hypothesis is strengthened, there is potential to learn about genetic radiation risks and to prevent similar effects in present and future exposure situations.

Keywords: Food contamination, Food export import, Human secondary sex ratio, Radiation induced genetic effects, Radioactive fallout

\section{Background}

\section{Sex ratio - a genetic indicator}

According to Schull and Neel [1-3], the uniqueness of the human sex ratio at birth as an indicator of genetic health or genetic detriment arises from the fact that maternal chemical or physical mutagenic exposure is expected to produce a sex ratio different from the sex ratio after paternal exposure. Therefore, the ratio of male to female offspring at birth may be a simple and noninvasive way to study and monitor the reproductive status of a population. Among others, environmental and

\footnotetext{
* Correspondence: scherb@helmholtz-muenchen.de Institute of Computational Biology, Helmholtz Zentrum Muenchen, German Research Center for Environmental Health, Neuherberg, Germany
}

occupational hazards can alter the sex ratio at birth. In a recently published comprehensive review article [4], more than 100 studies were evaluated including several investigations on ionizing radiation and chemicals. Among the occupational exposure studies concerning ionizing radiation, Hama et al. [5] considered 586 male radiologists in Japan. As a group, male radiologists tended to father a lower proportion of boys compared with the control group. Maconochie et al. [6] looked at over 46,000 children born to UK nuclear industry workers and found no statistically significant alterations of the sex ratio. However, in a considerably larger study of 260,060 births to fathers employed at Sellafield, Dickinson et al. [7] reported that those men sired a greater proportion of boys 
than would be expected. An effect was also observed in fathers with recorded doses exceeding $10 \mathrm{mSv}$ before conception. While this may reflect a true statistical association, it is also possible that it may be a chance finding due to imprecision in the dose estimates and consequent misclassification. Animal experiments shed light on the extreme complexity of radiation induced genetic effects. Irradiation of female mice with fission neutrons by Russel et al. [8] has shown that the length of the period between irradiation and conception has a striking effect on the mutation frequencies seen in the offspring. In conceptions seven weeks after irradiation, mutation frequencies turned out to be relatively high. Havenstein et al. [9] have shown that radiation exposure of spermatogonia entailed a real change in the sex ratio in the rat. Nevertheless, Russell and Havenstein doubt that their positive results received with mice and rats will apply to humans. Neel et al. [10] studied children of parents exposed to atomic bombs in Japan on the basis of revised radiation dose estimates. These revised estimates indicated that humans are less sensitive to genetic effects from radiation than has been assumed on the basis of extrapolations from animal experiments. However, this point of view has been challenged by Vogel [11].

According to Scholte and Sobels [12], one of the few methods available for studying the genetic effects of ionizing radiation in man in sufficiently large populations is the observation of changes in the sex ratio among offspring from irradiated parents. Radiation induced lethal factors of varying degree of dominance on the $\mathrm{X}$ chromosome depending on whether an impaired X chromosome is derived from the mother or the father impact the formation and the survival probability of the female zygote, entailing more or less girls at birth, which can also be interpreted as less or more boys, respectively. According to theory [13], Cox found reduced offspring sex ratio (deficit of boys) in irradiated women [14], and James emphasized "ionizing radiation is the only reproductive hazard, which causes men to sire an excess of sons" [15]. In addition to lethal factors on the X chromosome, Scholte and Sobels [12] allude to nondisjunction resulting in $\mathrm{X} 0$ genotypes, which are non-viable in man and, thus, may also distort the birth sex ratio. As Down syndrome is a well-known consequence of meiotic nondisjunction, evidence of increased nondisjunction across Europe after Chernobyl is obtained from increased Down syndrome prevalence at birth [16]. Except in societies where selective abortion skews the sex ratio [17-19], approximately 104 to 106 boys are born for every 100 girls. In humans, on the one hand, the sex ratio at birth is essentially constant at the secular population level [20], but on the other hand, considerable variability of the sex ratio may be observed under a variety of specific circumstances. A lot of hypothetical sex ratio determinants and methodological challenges assessing them have been discussed in the literature [21]. However, Steiner [22] points out that proposed determinants showed associations in small samples that could not be replicated in larger populations. This, of course, may be due to insufficient statistical power, i.e., large second kind error probabilities due to small effects or too small study-populations.

\section{Offspring sex ratio - in atomic bomb survivors and in parents hit by nuclear testing}

Schull and Neel performed studies in the sex ratio among infants born to survivors of the atomic bombings of Hiroshima and Nagasaki, Japan. The first study published in 1958 [1] revealed significant changes in the sex ratio of these children. The second study [2] still found a small effect in the early post-bomb years, which had apparently disappeared in later years. Schull et al. [2] explained: "One can argue that a small early effect has disappeared or that the original observation had no biological significance". Mudie et al. [23] studied the sex ratio in the 11,464 offspring of parents with chronic radiation exposure from nuclear testing in Kazakhstan. They conclude: "No significant association was found between radiation exposure level and sex ratio, but some previously suggested demographic factors were positively associated with sex ratio." However, looking at the tabulated Mudie et al. data, we can see that the sex ratio increases linearly from 1.04 at less than $20 \mathrm{cSv}$, to 1.05 at $20-40 \mathrm{cSv}$, to 1.08 at $40-60 \mathrm{cSv}$, and to 1.12 at more than $60 \mathrm{cSv}$. See Figure 1 for a sample logistic regression analysis of this data set using the statistical freeware package " $R$ ". For an introduction to logistic regression see [24]. Although the Mudie et al. result was not significant, it is nevertheless consistent with a positive association of the sex ratio with radiation exposure; quite similar in principle to what we have found at the ecological district level in Germany after Chernobyl [25].

\section{Sex ratio in Europe after Chernobyl}

Motivated by Schull and Neel's publication [1] and since we had found increased stillbirths and birth defects after Chernobyl [26,27], we have been investigating the influence of ionizing radiation on the human birth sex ratio for several years. By a pilot study, we assessed the trends in the sex ratio in several selected European countries with emphasis on the Chernobyl Nuclear Power Plant accident [25]. As this study yielded positive results including an ecological dose response association between fallout and the sex ratio, we investigated the behavior of the sex ratio after the atmospheric atomic bomb tests and after Chernobyl more thoroughly for longer time periods and on a global scale. One of the main results was a jump of the sex ratio after Chernobyl in all of 


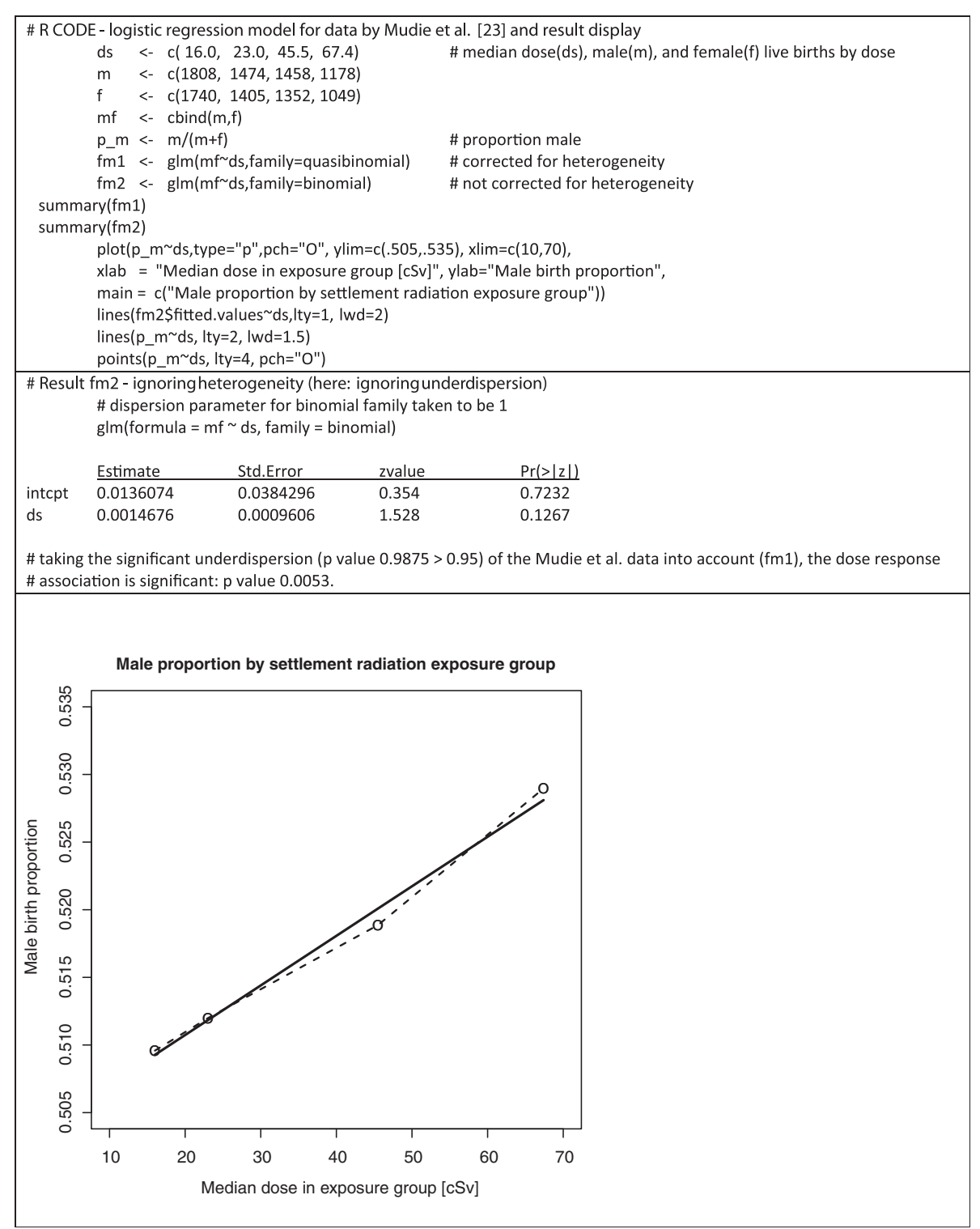

Figure $1 \mathrm{R}$ code for sample logistic regression, result summary, and graphical display of the Mudie et al. data [23].

Europe, including Russia (Figure 2), and a subsequent trend reversal from 1987 onward. No such similar effect was seen in the less affected USA. This investigation [28] confirmed our opening study [25]. For debate and further findings see [29-32]. Peterka et al. [33] reported a sharply reduced male live birth proportion in November 1986 in the Czech Republic. The decreased male proportion restricted to a single month is in contrast to the long term increased male proportion across Europe. Moreover, replication of the Peterka et al. study with Bavarian data yields an estimate of the male proportion in November 1986 identical to the overall mean. Therefore, the finding by Peterka et al. could not be supported [34].

\section{Sex ratio in Cuba after Chernobyl}

\section{S. J. Venero Fernandez et al.}

An intriguing new example of an escalated sex ratio after Chernobyl has been published in the American Journal of Epidemiology by Cuban scientists [35]. In Cuba, the sex ratio is subject to a strong uptick immediately after Chernobyl in the year 1987 (Figure 3). Moreover, this jump in the sex ratio is followed by a long-lasting elevated trend up to the year 2000 when the Cuban sex ratio approaches $1.06-1.07$, which are nearly preChernobyl values. Contrary to the Trivers-Willard hypothesis postulating decreasing sex ratios during economic hardship [36], Venero Fernandez et al. [35] try to explain the striking sex ratio increase in Cuba by a sociological 


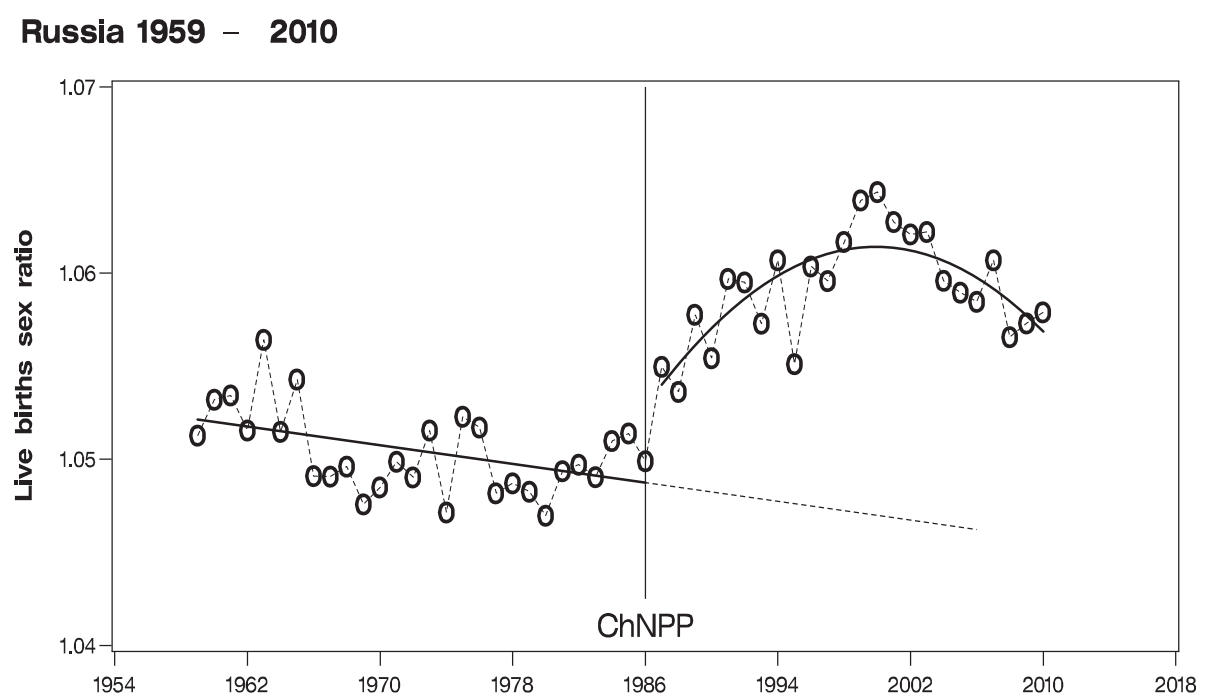

Figure 2 The human secondary sex ratio in the Russian Federation including logistic regression model; ChNPP: Chernobyl Nuclear Power Plant explosion.

aspect, namely by the economic depression in Cuba ('Special Period'), which started in 1991 after the dissolution of the Soviet Union and the COMECON. However, the strong increase from the stable sex ratio of 1.0585 in the 29 -years $1958-1986$ to the escalated average sex ratio of $1.0864(1.0785,1.0944), \mathrm{p}$ value $<0.0001$ in the 4-years period 1987 - 1990 can hardly be explained neither by chance nor by economic depression. Chance can be excluded as this jump from the level in 1958 - 1986 to the level in 1987 - 1990 measures more than 5 standard errors and economic depression can be excluded as its onset occurred only 4 years after the sex ratio jump, see the GDP curve in Figure 2 in [35].

\section{A. J. Wilcox and D. D. Baird}

Together with the publication by Cuban scientists, an invited commentary by two American scientists appeared in the same issue of the American Journal of Epidemiology. Wilcox and Baird question the importance of the sex ratio as an environmental health indicator and try to explain the strong increase in the sex ratio in Cuba by sex selective abortions [37]. Abortions in Cuba have been described in the scientific literature [38] but

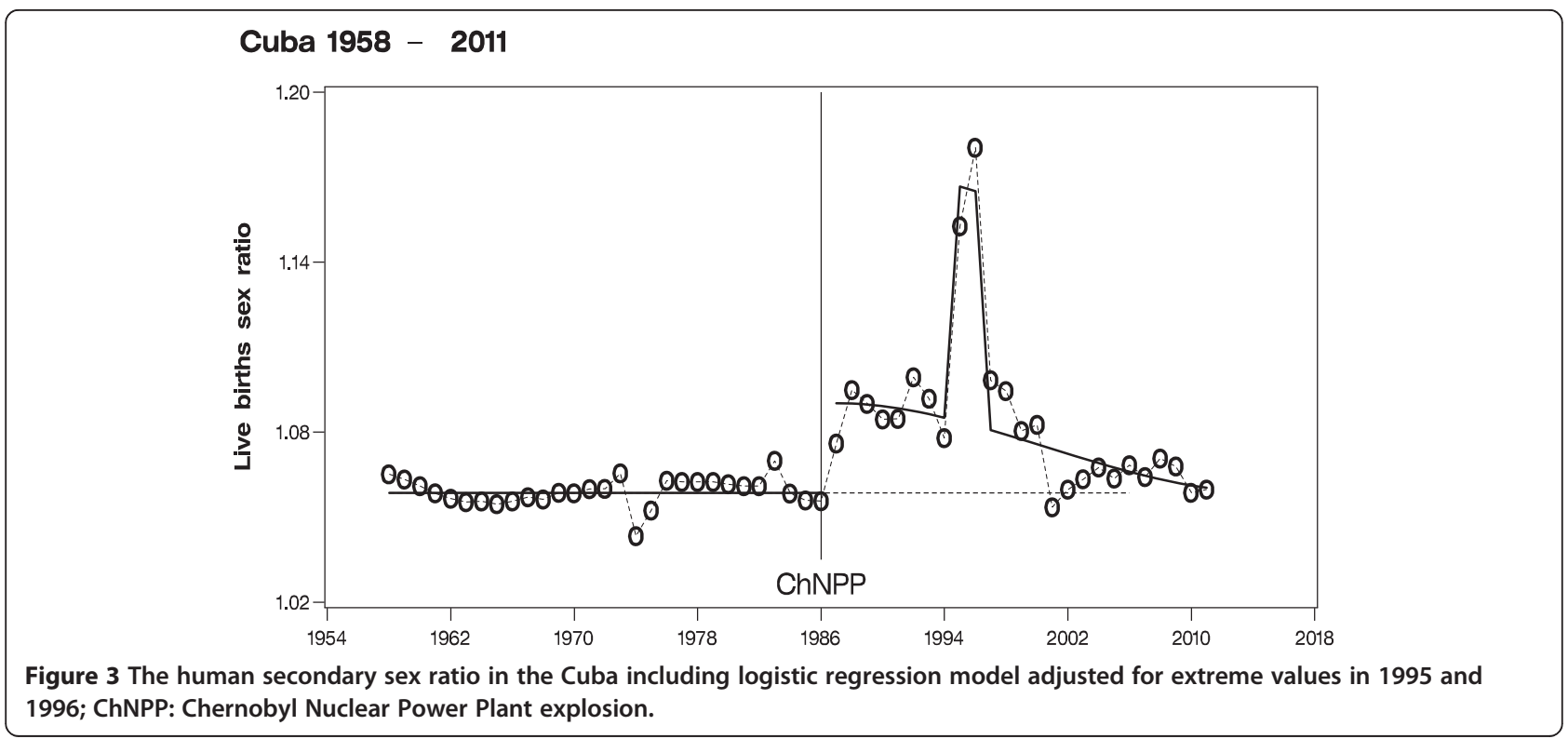


not gender-specific ones [39]. Therefore, the alternative explanation offered by Wilcox and Baird, sex selective abortion, is implausible as this practice is unusual in Cuba. Also, Wilcox and Baird do not address the question as to why sex selective abortion starts in 1987, which is not congruent with the 'Special Period' that began only in or after 1990 .

\section{Simpson}

Simpson [40] attempts to explain the effect by a technical artifact of the data recording procedure, possibly caused by and acting from the ending of the former Soviet Union in 1990: "Russia's breaking of economic trade agreements with Cuba in 1990 was followed by a tightening embargo on trade from the US government ... As one specific example, there were insufficient funds to continue to import a gummed 2-page form that accurately replicated writing onto a copy. This form had been used to record birth details in hospitals, where over 99\% of births in Cuba occurred throughout this period". Again, Simpson oversees the significant uptick of the sex ratio in 1987 together with the even stronger increases in 1988 through 1990, clearly emerging before the Soviet breakdown. Quantifying this peculiar and stable 4-year increase from 1987 - 1990 yields a sex ratio ratio (or better sex odds ratio) of 1.0263 (1.0209, 1.0318), p value $<0.0001$. Therefore, Simpson's explanation does not apply to the period from 1987 through 1990, and thus his explanation may perhaps only partly account for the escalated sex ratio in Cuba from 1991 onward. Also, Simpson does not make sufficiently clear why a presumable random noise imposed on the recordings of the births' sexes should be biased in favor of boys; one would rather expect non-differential misclassification instead. Eventually, one might speculate that Simpson's explanation is to the point in principle, but only for the years 1995/1996. However, this is not important for our hypothesis as we focus on the years 1987/1988, and Simpson did not restrict his argument to 1995/1996. The adjustment for the years 1995 and 1996 in our Cuban sex ratio trend model (Figure 3) is equivalent to excluding those years as outliers. Therefore, excluding these outliers would not change our effect estimates, confidence limits, and p-values. Consequently, our inference from the Cuban sex ratio data is independent from those outliers, and is thus somewhat conservative. In summary, no convincing explanation of the strong and transient sex ratio increase in Cuba from 1987 to 2000 has been offered in the literature as yet, neither by the authors themselves nor by the annotators.

\section{Presentation of the hypothesis}

There is no denying the fact that a strong and highly significant increase in the human sex ratio at birth in Cuba immediately after 1986 exists, and 1986 was the year of the Chernobyl accident. A sex ratio increase after 1986 also holds true for all of Europe, and in particular for single southern and eastern European countries, among them Russia [28,32]. The question arises whether any more or less smooth social, political, economic, etc. factor, could entail such an abrupt consequence across Europe and in Cuba simultaneously. Therefore, we hypothesize that the mechanism might be a direct biophysical one that acts synchronously in Europe, in Russia, and in Cuba from 1987 onward. It must not be overseen that according to the Trivers-Willard hypothesis [36], the effect in Cuba is in the wrong direction. Economic depression would lead to a decrease not an increase in the sex ratio. On the other hand, according to James [15], radiation is the only known reproductive hazard that increases the sex ratio. From this perspective, the previous explanation attempts are not convincing. Therefore, we are of the opinion that there is a direct effect of radioactively contaminated food and possibly feeding stuff exported from the former Soviet Union or from other Chernobyl affected European or Asian countries to Cuba. During the eighties of the last century in Cuba more than 50\% of the food imports were provided by the former USSR. In the Seattle PostIntelligencer, Buncombe [41] explained: "Cuba's economy was extraordinarily reliant on subsidies from its political older brother, the Soviet Union. Its agriculture was designed with one aim in mind - namely to produce as much sugar cane as possible, which the Soviets bought at more than five times the market price, in addition to purchasing 95 percent of its citrus crop and 73 percent of its nickel. In exchange, the Soviets provided Cuba with 63 percent of its food imports and 90 percent of its petrol. Such a relationship made Cuba extraordinarily vulnerable". From statistics published by the Food and Agriculture Organization of the United Nations (FAO, http://faostat.fao.org/), we can see for example that in the period 1986 - 1989 evaporated milk in the range of over 100,000 tons was imported in Cuba from the former USSR (Table 1). Interestingly, the amount of imported milk doubled just in 1987, however, at half the price compared to the remaining years.

Ross [42] explained the difficult food supply situation in Cuba during the so-called "Periodo Especial", that is to say in the early years of the 1990s. Cuba had lost Soviet and Eastern Bloc trade preferences and per capita caloric consumption had fallen about $20 \%$. Conversely, this means that the equivalent amount of food representing $20 \%$ of per capita caloric consumption can be attributed to imports from the Soviet Union before the crisis, especially from 1987 to 1990 . During the 'Special Period, imported food has been a relevant factor of feeding Cuba's population. Imports of dairy products, corn, wheat, wheat flour, fed grains and barley declined in the 
Table 1 Evaporated whole milk exports from the former USSR to Cuba in the period 1986 - 1989, see http://faostat.fao.org/

\begin{tabular}{|c|c|c|c|c|c|c|c|}
\hline Reporter & Partner & Item & Element & Year & Units & Value & Flag \\
\hline USSR & Cuba & Milk whole Evp & Export quantity & 1986 & Tonnes & 21086 & Official data \\
\hline USSR & Cuba & Milk whole Evp & Export quantity & 1987 & Tonnes & 55543 & Official data \\
\hline USSR & Cuba & Milk whole Evp & Export quantity & 1988 & Tonnes & 21378 & Official data \\
\hline USSR & Cuba & Milk whole Evp & Export quantity & 1989 & Tonnes & 20624 & Official data \\
\hline USSR & Cuba & Milk whole Evp & Export value & 1986 & 1000 US\$ & 20996 & Official data \\
\hline USSR & Cuba & Milk whole Evp & Export value & 1987 & 1000 US\$ & 24588 & Official data \\
\hline USSR & Cuba & Milk Whole Evp & Export value & 1988 & 1000 US\$ & 24738 & Official data \\
\hline USSR & Cuba & Milk whole Evp & Export value & 1989 & 1000 US\$ & 22855 & Official data \\
\hline
\end{tabular}

mid-1990s. We, therefore, presume that Cuba's imported food and probably feed products before the onset of the crisis were contaminated with radioactive elements from affected European and Asian countries after the Chernobyl accident. Comparison of Figure 1 and Figure 2 indicates that the Cuban effect, although much stronger than the overall Russian effect, seems to vanish somewhat earlier than the effect in Russia. This fits the assumption that 'only' imported food was transitionally contaminated and not the whole surface of Cuba. It is even conceivable that contaminated produce found boosted its way to Cuba simply because it was cheaper and Cuba underwent difficult economic conditions, which prevented it from taking effective counter measures to protect its people. The causal interpretation by Venero Fernandez et al. [35]: "These data suggest that, in Cuba, contrary to the Trivers-Willard hypothesis [36], the human population responded to conditions of scarcity by increasing the ratio of males to females at live birth" goes along with our view on this problem, however, in a more concrete biological sense: We are of the opinion that radioactively contaminated human food and probably animal feed induced the increase in the human sex ratio at birth in Cuba after Chernobyl. Unlike other countries [43] and due to political constraints as well as its overall poor position, Cuba as a nation had not the necessary economic and political strength to circumvent the threat of contaminated consumer products after Chernobyl by imposing safe control measures on imports from abroad.

\section{Testing of the hypothesis}

\section{Synoptic analysis of Russian and Cuban secular sex ratio} trends

We compare the sex ratio trends of Cuba (1958 - 2011) and Russia (1959 - 2010) and quantify pertinent effectparameters of those trends, especially the jumps in 1987. The relevant annual births figures by gender are presented in Table 2 (for the original data sources see: http://www.one.cu/anuariodemografico2011.htm, http:// data.euro.who.int/hfadb/, and http://www.mortality.org).
Sex ratio in Russia follows an overall linear decline from 1959 to 1986 with a reduction per 10 years of $0.12 \%$ $(0.04,0.20)$, p value 0.0021 (Figure 2). We may estimate a significant jump of the sex ratio from 1986 to 1987 of $0.51 \%(0.28,0.75)$, p value $<0.0001$. From 1987 onward, there is a long-term sex ratio increase to maximum values in 1999/2000 of nearly 1.065 and a subsequent decline after the year 2000. A parsimonious model for the partial Russian sex ratio trend after Chernobyl is a $2^{\text {nd }}$ degree polynomial, i.e. a parabola with $\mathrm{p}$ value $<0.0001$. If the decline starting in 2000 will continue linearly and undisturbed, the Russian sex ratio is to resume normal pre Chernobyl values near 1.05 beyond the year 2020 . Sex ratio in Cuba from 1958 to 1986 follows an essentially constant trend with no strong overall upward or downward tendency before Chernobyl (Figure 3). In Cuba, we may estimate a jump in 1987 of 2.99\%; (2.39, 3.60 ), $\mathrm{p}$ value $<0.0001$, which is six times the jump estimate of the Russian sex ratio in 1987. Moreover, there are still even stronger increases in Cuba in 1995 and 1996 exceeding a sex ratio of 1.15. A well-fitting, however less parsimonious model for the partial Cuban sex ratio trend after Chernobyl consists of a $3^{\text {rd }}$ degree polynomial adjusted for the extreme values in 1995 and 1996. This model approaches nearly normal pre-Chernobyl values of 1.06 around the year 2010. It is, therefore, quite obvious that in Cuba and Russia the sex ratio trends that had existed before the Chernobyl accident are markedly disturbed immediately after Chernobyl albeit the temporal patterns of the sex ratio changes as well as the maximum values taken on differ considerably between the two countries.

Contaminated food on the world markets after Chernobyl The fact that contaminated food was in transit on the world markets [43] is documented especially for Mexico and Brazil where thousands of tons of contaminated milk powder had to be confiscated after the detection of violations of legal contamination limits for Cs-137. In 1988 in Mexico, the state National Company of People's 
Table 2 Annual live births by gender and sex ratio for Cuba and Russia

\begin{tabular}{|c|c|c|c|c|c|c|c|c|}
\hline \multirow[t]{2}{*}{ Year } & \multicolumn{4}{|c|}{ Cuba } & \multicolumn{4}{|c|}{ Russian Federation } \\
\hline & Total & Male & Female & Sex ratio & Total & Male & Female & Sex ratio \\
\hline 1958 & 176510 & 91040 & 85470 & 1.0652 & & & & \\
\hline 1959 & 191207 & 98538 & 92669 & 1.0633 & 2796228 & 1433060 & 1363168 & 1.0513 \\
\hline 1960 & 211620 & 108940 & 102680 & 1.0610 & 2782353 & 1427225 & 1355128 & 1.0532 \\
\hline 1961 & 231811 & 119194 & 112617 & 1.0584 & 2662135 & 1365700 & 1296435 & 1.0534 \\
\hline 1962 & 249113 & 127982 & 121131 & 1.0566 & 2482539 & 1272461 & 1210078 & 1.0516 \\
\hline 1963 & 260224 & 133615 & 126609 & 1.0553 & 2331505 & 1197738 & 1133767 & 1.0564 \\
\hline 1964 & 266554 & 136880 & 129674 & 1.0556 & 2121994 & 1087619 & 1034375 & 1.0515 \\
\hline 1965 & 267611 & 137361 & 130250 & 1.0546 & 1990520 & 1021560 & 968960 & 1.0543 \\
\hline 1966 & 264022 & 135580 & 128442 & 1.0556 & 1957403 & 1002152 & 955251 & 1.0491 \\
\hline 1967 & 257942 & 132550 & 125392 & 1.0571 & 1851041 & 947686 & 903355 & 1.0491 \\
\hline 1968 & 251857 & 129376 & 122481 & 1.0563 & 1816509 & 930239 & 886270 & 1.0496 \\
\hline 1969 & 246005 & 126506 & 119499 & 1.0586 & 1847592 & 945265 & 902327 & 1.0476 \\
\hline 1970 & 237019 & 121875 & 115144 & 1.0585 & 1903713 & 974392 & 929321 & 1.0485 \\
\hline 1971 & 256014 & 131733 & 124281 & 1.0600 & 1974637 & 1011337 & 963300 & 1.0499 \\
\hline 1972 & 247997 & 127610 & 120387 & 1.0600 & 2014638 & 1031422 & 983216 & 1.0490 \\
\hline 1973 & 226005 & 116584 & 109421 & 1.0655 & 1994621 & 1022369 & 972252 & 1.0515 \\
\hline 1974 & 203066 & 103687 & 99379 & 1.0433 & 2079812 & 1063857 & 1015955 & 1.0471 \\
\hline 1975 & 192941 & 98933 & 94008 & 1.0524 & 2106147 & 1079901 & 1026246 & 1.0523 \\
\hline 1976 & 187555 & 96637 & 90918 & 1.0629 & 2146711 & 1100411 & 1046300 & 1.0517 \\
\hline 1977 & 168960 & 87039 & 81921 & 1.0625 & 2156724 & 1103729 & 1052995 & 1.0482 \\
\hline 1978 & 148249 & 76369 & 71880 & 1.0625 & 2179030 & 1115420 & 1063610 & 1.0487 \\
\hline 1979 & 143551 & 73949 & 69602 & 1.0625 & 2178542 & 1114937 & 1063605 & 1.0483 \\
\hline 1980 & 136900 & 70496 & 66404 & 1.0616 & 2202779 & 1126666 & 1076113 & 1.0470 \\
\hline 1981 & 136211 & 70120 & 66091 & 1.0610 & 2236608 & 1145239 & 1091369 & 1.0494 \\
\hline 1982 & 159759 & 82242 & 77517 & 1.0610 & 2328044 & 1192252 & 1135792 & 1.0497 \\
\hline 1983 & 165284 & 85433 & 79851 & 1.0699 & 2478322 & 1268820 & 1209502 & 1.0490 \\
\hline 1984 & 166281 & 85498 & 80783 & 1.0584 & 2409614 & 1234760 & 1174854 & 1.0510 \\
\hline 1985 & 182067 & 93511 & 88556 & 1.0560 & 2375147 & 1217322 & 1157825 & 1.0514 \\
\hline 1986 & 166049 & 85274 & 80775 & 1.0557 & 2485915 & 1273213 & 1212702 & 1.0499 \\
\hline 1987 & 179477 & 93023 & 86454 & 1.0760 & 2499974 & 1283425 & 1216549 & 1.0550 \\
\hline 1988 & 187911 & 98210 & 89701 & 1.0949 & 2348494 & 1204907 & 1143587 & 1.0536 \\
\hline 1989 & 184891 & 96428 & 88463 & 1.0900 & 2160559 & 1110602 & 1049957 & 1.0578 \\
\hline 1990 & 186658 & 97113 & 89545 & 1.0845 & 1988858 & 1021248 & 967610 & 1.0554 \\
\hline 1991 & 173896 & 90482 & 83414 & 1.0847 & 1794626 & 923319 & 871307 & 1.0597 \\
\hline 1992 & 157349 & 82399 & 74950 & 1.0994 & 1587644 & 816757 & 770887 & 1.0595 \\
\hline 1993 & 152238 & 79459 & 72779 & 1.0918 & 1378983 & 708689 & 670294 & 1.0573 \\
\hline 1994 & 147265 & 76394 & 70871 & 1.0779 & 1408159 & 724818 & 683341 & 1.0607 \\
\hline 1995 & 147170 & 78803 & 68367 & 1.1526 & 1363806 & 700191 & 663615 & 1.0551 \\
\hline 1996 & 140276 & 75941 & 64335 & 1.1804 & 1304638 & 671430 & 633208 & 1.0604 \\
\hline 1997 & 152681 & 79917 & 72764 & 1.0983 & 1259943 & 648195 & 611748 & 1.0596 \\
\hline 1998 & 151080 & 78948 & 72132 & 1.0945 & 1283292 & 660842 & 622450 & 1.0617 \\
\hline 1999 & 150785 & 78308 & 72477 & 1.0805 & 1214689 & 626149 & 588540 & 1.0639 \\
\hline 2000 & 143528 & 74610 & 68918 & 1.0826 & 1266800 & 653146 & 613654 & 1.0644 \\
\hline
\end{tabular}


Table 2 Annual live births by gender and sex ratio for Cuba and Russia (Continued)

\begin{tabular}{|c|c|c|c|c|c|c|c|c|}
\hline 2001 & 138718 & 71166 & 67552 & 1.0535 & 1311604 & 675750 & 635854 & 1.0627 \\
\hline 2002 & 141276 & 72686 & 68590 & 1.0597 & 1396967 & 719511 & 677456 & 1.0621 \\
\hline 2003 & 136795 & 70500 & 66295 & 1.0634 & 1477301 & 760934 & 716367 & 1.0622 \\
\hline 2004 & 127192 & 65674 & 61518 & 1.0676 & 1502477 & 772973 & 729504 & 1.0596 \\
\hline 2005 & 120716 & 62219 & 58497 & 1.0636 & 1457376 & 749554 & 707822 & 1.0590 \\
\hline 2006 & 111323 & 57502 & 53821 & 1.0684 & 1479637 & 760831 & 718806 & 1.0585 \\
\hline 2007 & 112472 & 57984 & 54488 & 1.0642 & 1610122 & 828772 & 781350 & 1.0607 \\
\hline 2008 & 122569 & 63378 & 59191 & 1.0707 & 1713947 & 880543 & 833404 & 1.0566 \\
\hline 2009 & 130036 & 67153 & 62883 & 1.0679 & 1761687 & 905380 & 856307 & 1.0573 \\
\hline 2010 & 127746 & 65692 & 62054 & 1.0586 & 1788948 & 919639 & 869309 & 1.0579 \\
\hline 2011 & 133067 & 68464 & 64603 & 1.0598 & & & & \\
\hline
\end{tabular}

Subsistence (CONASUPO) distributed 2,436 tons of milk powder contaminated with Cs-137 after Chernobyl. The company was able to recall or otherwise account for 1,497 tons, and the whereabouts of the rest of the milk powder is unknown [44]. In 1987 in Brazil, import of powdered milk from seven European countries had to be stopped after its Cs-137 contamination due to the Chernobyl accident became known and large amounts of milk powder had already been bought by consumers [45]. We are not aware of any comparable counter measures taken in Cuba to protect people from imported Chernobyl contaminated products. This might be explained in general by the close political connection of Cuba to the Soviet Union at that time, and, in particular, by the intent to build a number of nuclear power plants in Cuba with the help of the USSR to overcome the Cuban dependence on imported oil [46]. That radioactively contaminated food, animal feed, and general consumer products were imported to Cuba can be tested in two ways: firstly, by reconstruction of export/import pathways from Chernobyl affected countries to Cuba in analogy to our Table 1, and secondly, by radiological analyses of possible general remains for Cs-137, and teeth of children and bones of deceased for $\mathrm{Sr}-90$. The radioactive Cs-137 and Sr-90 isotopes have sufficiently long half-lives of approximately 30 years that makes them suited for that purpose.

\section{Reasoning by analogy}

There have been positive epidemiological findings after Chernobyl $[16,26,27,47,48]$. Therefore, our hypothesis can be tested by scrutinizing Cuban public health statistics for increases after 1986: e.g. stillbirths, perinatal mortality, and infant deaths including corresponding sex ratios. Historical hospital records may reflect increases in disease frequencies: e.g. cancer, diabetes, and heart diseases. Finally, children's hospitals may have recorded data on the occurrence of chromosome anomalies and birth defects: e.g. Down syndrome, malformation of the heart, and cleft lip and palate.

\section{Limitations of the hypothesis}

One of the major limitations of the hypothesis and its testability is of course the long time period of now 27 years that have passed since the Chernobyl accident. It may prove difficult if not impossible to retrospectively throw light on imports to Cuba. Not to speak of the concrete estimation of the amounts of relevant produce from contaminated parts of Europe and Asia actually processed and consumed in Cuba. Also, it may be difficult to distinguish between more or less affected groups in the Cuban population. Did those who hypothetically ate the most contaminated food have the highest sex ratios among their offspring? This question cannot be answered by the as yet published highly aggregated data. It can possibly be answered if historical regional gender specific birth statistics and regional consumption statistics were available and could be linked appropriately. Another major limitation is the general lack of firm evidence that ionizing radiation increases the human sex ratio. It is even possible that certain kinds of radiation exposures decrease the sex ratio or act neutral on gender. Detailed animal experiments have clearly shown the enormous complexity of the diverse ionizing radiation exposures and mutational outcomes $[8,9,11,13]$. The biologic, genetic, and social details in which way mankind sustains a stable gender proportion are largely unknown.

\section{Implications of the hypothesis}

If the evidence for the hypothesis can be strengthened by appropriate investigations, this would corroborate similar findings in Europe and Asia. Since in contrast to Europe, the Cuban surface was not contaminated by Chernobyl fallout, the effect must essentially be due to 
internal radiation, i.e. so called internal emitters, following intake of radioactively contaminated food. This special situation could help to better understand etiologic pathways from food contamination to radiation induced genetic effects. Also, the hypothesis if corroborated would weaken the prevailing opinion, e.g. held by UNSCEAR [49], that radiation induced genetic effects have yet to be detected in humans. If the hypothesis can be confirmed, the Cuban experience dealt with in this paper could be a warning with regard to Fukushima and the unresolved problem of the now existing huge amount of radioactive waste worldwide.

\section{Abbreviations \\ ChNPP: Chernobyl Nuclear Power Plant; COMECON: Council for Mutual Economic Assistance; CONASUPO: Compañía Nacional de Subsistencias Populares; Cs: Cesium; cSv: 1/100 sievert; FAO: Food and Agriculture Organization; GDP: Gross domestic product; Sr: Strontium; UNSCEAR: United Nations Scientific Committee on the Effects of Atomic Radiation USSR: Union of Soviet Socialist Republics; X: X chromosome; Y: Y chromosome.}

\section{Competing interests}

The authors declare that they have no competing interests.

\section{Authors' contributions}

$\mathrm{KV}$ encountered the publications on increased sex ratio in Cuba, had the idea to publish a comment or a hypothesis, and contributed to the writing of the paper. RK investigated the FAO statistics, further related statistics, provided Table 1, and also contributed to the writing of the paper. HS conducted the statistical analyses and wrote the paper. All authors read and approved the final version of the manuscript.

Received: 26 February 2013 Accepted: 14 August 2013

Published: 15 August 2013

\section{References}

1. Schull WJ, Neel JV: Radiation and the sex ratio in man. Science 1958, 128:343-348.

2. Schull WJ, Neel JV, Hashizume A: Some further observations on the sex ratio among infants born to survivors of the atomic bombings of Hiroshima and Nagasaki. Am J Hum Genet 1966, 18:328-338.

3. Neel JV, Schull WJ: The Children of atomic bomb survivors: a genetic study. Washington, D.C.: National Academy Press; 1991.

4. Terrell ML, Hartnett KP, Marcus M: Can environmental or occupational hazards alter the sex ratio at birth? A systematic review. Emerging Health Threats Journal 2011, 4:1-18.

5. Hama $Y$, Uematsu M, Sakurai $Y$, Kusano S: Sex ratio in the offspring of male radiologists. Acad Radiol 2001, 8:421-424.

6. Maconochie N, Roman E, Doyle P, Davies G, Smith PG, Beral V: Sex ratio of nuclear industry employees' children. Lancet 2001, 357:1589-1591.

7. Dickinson $\mathrm{HO}$, Parker $L$, Binks $K$, Wakeford $R$, Smith J: The sex ratio of children in relation to paternal pre-conceptional radiation dose: a study in Cumbria, northern England. J Epidemiol Community Health 1996, 50:645-652.

8. Russell WL: Effect of the interval between irradiation and conception on mutation frequency in female mice. Proc Natl Acad Sci USA 1965 54:1552-1557.

9. Havenstein GB, Taylor BA, Hansen JC, Morton NE, Chapman AB: Genetic effects of cumulative $x$ irradiation on the secondary sex ratio of the laboratory rat. Genetics 1968, 59:255-274.

10. Neel JV Schull WJ, Awa AA Satoh C, Kato H Otake M, Yoshimoto Y. The children of parents exposed to atomic bombs: estimates of the genetic doubling dose of radiation for humans. Am J Hum Genet 1990 46:1053-1072

11. Vogel F: Risk calculations for hereditary effects of ionizing radiation in humans. Hum Genet 1992, 89:127-146.
12. Scholte PJ, Sobels FH: Sex ratio shifts among progeny from patients having received therapeutic X-radiation. Am J Hum Genet 1964, 16:26-37.

13. Vogel F, Motulsky AG: Human Genetics. Berlin Heidelberg New York Tokyo: Springer; 1986.

14. Cox DW: An investigation of possible genetic damage in the offspring of women receiving multiple diagnostic pelvic X rays. Am J Hum Genet 1964, 16:214-230.

15. James $\mathrm{WH}$ : lonizing radiation and offspring sex ratio. J Epidemiol Community Health 1997, 51:340-341.

16. Sperling K, Neitzel H, Scherb H: Evidence for an increase in trisomy 21 (Down syndrome) in Europe after the Chernobyl reactor accident. Genet Epidemiol 2012, 36:48-55.

17. Hesketh $T$, Xing ZW: Abnormal sex ratios in human populations: causes and consequences. Proc Natl Acad Sci USA 2006, 103:13271-13275.

18. Zhou C, Wang XL, Zhou XD, Hesketh $T$ : Son preference and sex-selective abortion in China: informing policy options. Int J Publ Health 2012, 57:459-465

19. Sahni M, Verma N, Narula D, Varghese RM, Sreenivas V, Puliyel JM: Missing girls in India: infanticide, feticide and made-to-order pregnancies? Insights from hospital-based sex-ratio-at-birth over the last century. Plos one 2008, 3:e2224.

20. Ein-Mor E, Mankuta D, Hochner-Celnikier D, Hurwitz A, Haimov-Kochman R Sex ratio is remarkably constant. Fertility and sterility 2010, 93:1961-1965.

21. James $\mathrm{WH}$ : Hypotheses on the stability and variation of human sex ratios at birth. J Theor Biol 2012, 310:183-186.

22. Steiner AZ: Epidemiologic evidence for an ecological phenomenon. Fertil Steril 2012, 98:819-820.

23. Mudie NY, Gusev BI, Pivina LM, Schoemaker MJ, Rijinkova ON, Apsalikov KN, Swerdlow AJ: Sex ratio in the offspring of parents with chronic radiation exposure from nuclear testing in Kazakhstan. Radiat Res 2007, 168:600-607.

24. Hosmer DW, Lemeshow S: Applied Logistic Regression. New York: John Wiley \& Sons; 1989.

25. Scherb H, Voigt $K$ : Trends in the human sex odds at birth in Europe and the Chernobyl Nuclear Power Plant accident. Reprod Toxicol 2007, 23:593-599.

26. Scherb H, Weigelt E, Brüske-Hohlfeld I: European stillbirth proportions before and after the Chernobyl accident. Int J Epidemiol 1999, 28:932-940.

27. Scherb H, Weigelt E: Congenital malformation and stillbirth in Germany and Europe before and after the Chernobyl nuclear power plant accident. Environ Sci Pollut Res, Special Issue 2003, 1:117-125.

28. Scherb H, Voigt K: The human sex odds at birth after the atmospheric atomic bomb tests, after Chernobyl, and in the vicinity of nuclear facilities. Environ Sci Pollut Res int 2011, 18:697-707.

29. Kramer W: The human sex odds at birth after the atmospheric atomic bomb tests, after Chernobyl, and in the vicinity of nuclear facilities: comment. Environ Sci Pollut Res int 2012, 19:1332-1334

30. Scherb H, Voigt K: Response to W. Kramer: The human sex odds at birth after the atmospheric atomic bomb tests, after Chernobyl, and in the vicinity of nuclear facilities:comment. Environ Sci Pollut Res int 2012a, 19:1335-1340. doi:10.1007/s11356-011-0644-8.

31. Bochud $F$, Jung T: Comment on the human sex odds at birth after the atmospheric atomic bomb tests, after Chernobyl, and in the vicinity of nuclear facilities, Hagen Scherb \& Kristina Voigt Environ, Sci Pollut Res (2011) 18:697-707. Environ Sci Pollut Res int 2012, 19:2456-2459.

32. Scherb H, Voigt $\mathrm{K}$ : Comment on the human sex odds at birth after the atmospheric atomic bomb tests, after Chernobyl, and in the vicinity of nuclear facilities, Hagen Scherb \& Kristina Voigt, Environ Sci Pollut Res (2011) 18:697-707. Environ Sci Pollut Res int 2012, 19:4234-4241. doi:10.1007/s11356-012-0767-6.

33. Peterka M, Peterkova R, Likovsky Z: Chernobyl: prenatal loss of four hundred male fetuses in the Czech Republic. Reprod Toxicol 2004, 18:75-79.

34. Scherb H, Voigt K: Analytical ecological epidemiology: exposure-response relations in spatially stratified time series. Environmetrics 2009, 20:596-606.

35. Venero Fernandez SJ, Medina RS, Britton J, Fogarty AW: The association between living through a prolonged economic depression and the male:female birth ratio-a longitudinal study from Cuba, 1960-2008. Am J Epidemiol 2011, 174(12):1327-1331. doi:10.1093/aje/kwr357.

36. Trivers RL, Willard DE: Natural selection of parental ability to vary the sex ratio of offspring. Science 1973, 179:90-92. 
37. Wilcox AJ, Baird DD: Invited commentary: Natural versus unnatural sex ratios-a quandary of modern times. Am J Epidemiol 2011, 174(12):1332-1334. doi:10.1093/aje/kwr360.

38. Belanger D, Flynn A: The persistence of induced abortion in Cuba: exploring the notion of an "abortion culture". Stud Fam Plann 2009, 40:13-26.

39. Venero Fernandez SJ, Medina RS, Britton J, Fogarty AW: Fernandez et al. respond to "Natural Versus Unnatural Sex Ratios". Am J Epidemiol 2011, 174(12):1335. doi:10.1093/aje/kwr361.

40. Simpson L: Re: "The association between living through a prolonged economic depression and the male: female birth ratio-a longitudinal study from Cuba, 1960-2008" and "Invited commentary: natural versus unnatural sex ratios-a quandary of modern times". Am J Epidemio/ 2012 175(9):973. doi:10.1093/aje/kws142.

41. Buncombe A: Cuba's Agricultural Revolution an Example to the World. Seattle: Seattle Post-Intelligencer; 2006. http://www.commondreams.org/ views06/0813-23.htm, Accessed 23 April 2013.

42. Ross JE: Food Security in Cuba. In Cuba Today: Continuity and Change Since the 'Período Especial'. Edited by Font MA. New York: Bildner Center for Western Hemisphere Studies; 2004:115-125.

43. Bannink D: Contaminated foodstuffs dumped on world market. In WISE News Communique. Amsterdam: WISE-Amsterdam; 1991. http://www10.antenna.nl/ wise/index.html?http://www10.antenna.n//wise/349-50/conta.html.

44. Zamora G: Caso Conasupo: La Leche Radiactiva El Crimen Mas Atroz Contra El Pueblo Mexicano. Mexico: Editorial Planeta; 1997.

45. Anonymous: Brazilian federal court has banned the sales. Orlando Sentinel; 1987. http://articles.orlandosentinel.com/1987-01-13/news/ 0100130265 1_powdered-milk-cesium-radioactive.

46. Wikipedia: Juragua Nuclear Power Plant. In Juragua Nuclear Power Plant. Wikipedia; 2012. http://en.wikipedia.org/wiki/Juragua_Nuclear_Power_Plant (accessed 8/15/2013).

47. Busby C, Busby J, Rietuma D: Fukushima and Health: What to Expect. Green Audit Books; 2011. http://www.amazon.de/Fukushima-Health-ProceedingsInternational-Conference/dp/1897761171 (accessed 8/15/2013). ISBN -13: 978-1897761175.

48. Yablokov AV, Nesterenko VB, Nesterenko AV: Chernobyl: Consequences of the Catastrophe for People and the Environment. Berlin Heidelberg New York Tokyo: John Wiley and Sons; 2010.

49. UNSCEAR: Sources and effects of ionizing radiation, Report to the General Assembly, 6 June 2000. New York: United Nations; 2000

doi:10.1186/1476-069X-12-63

Cite this article as: Scherb et al:: Increased sex ratio in Russia and Cuba after Chernobyl: a radiological hypothesis. Environmental Health 2013 12:63.

\section{Submit your next manuscript to BioMed Central and take full advantage of:}

- Convenient online submission

- Thorough peer review

- No space constraints or color figure charges

- Immediate publication on acceptance

- Inclusion in PubMed, CAS, Scopus and Google Scholar

- Research which is freely available for redistribution 